\title{
Therapeutic cloning: promises and issues
}

\author{
Charlotte Kfoury*
}

\begin{abstract}
Advances in biotechnology necessitate both an understanding of scientific principles and ethical implications to be clinically applicable in medicine. In this regard, therapeutic cloning offers significant potential in regenerative medicine by circumventing immunorejection, and in the cure of genetic disorders when used in conjunction with gene therapy. Therapeutic cloning in the context of cell replacement therapy holds a huge potential for de novo organogenesis and the permanent treatment of Parkinson's disease, Duchenne muscular dystrophy, and diabetes mellitus as shown by in vivo studies. Scientific roadblocks impeding advancement in therapeutic cloning are tumorigenicity, epigenetic reprogramming, mitochondrial heteroplasmy, interspecies pathogen transfer, low oocyte availability. Therapeutic cloning is also often tied to ethical considerations concerning the source, destruction and moral status of IVF embryos based on the argument of potential. Legislative and funding issues are also addressed. Future considerations would include a distinction between therapeutic and reproductive cloning in legislative formulations.
\end{abstract}

KEYWORDS: therapeutic cloning, SCNT, cell replacement therapy, gene therapy, mitochondrial heteroplasmy, oocyte availability, biomedical ethics

\section{INTRODUCTION}

The advancement in biotechnologies and stem cell research, although encountering many scientific difficulties, legal constraints and ethical roadblocks, offers a tremendous potential in regenerative medicine and in the treatment of genetic defects. Therapeutic cloning is the transfer of nuclear material isolated from a somatic cell into an enucleated oocyte in the goal of deriving embryonic cell lines with the same genome as the nuclear donor. Somatic cell nuclear transfer (SCNT) products have histological compatibility with the nuclear donor, which circumvents, in clinical applications, the use of immunosuppressive drugs with heavy side-effects. While the goal of reproductive cloning is the creation of a person, the purpose of therapeutic cloning is to generate and direct the differentiation of patient-specific cell lines isolated

*To whom correspondence should be addressed: Charlotte Kfoury 26 Hillcrest, Pointe-Claire, Montreal, Quebec, H9S5E5, Canada

Email: charlotte.kfoury@mail.mcgill.ca

Tel: (514) 694-4378 from an embryo not intended for transfer in utero. Therapeutic cloning, through the production of these autologous nuclear-transfer embryonic stem cells (ntESC), offers great promises for regenerative and reproductive medicine, and in gene therapy, as a vector for gene-delivery. This review focuses on the recent breakthroughs in research based on therapeutic cloning, their feasibility, and their potential applications in medicine. The second part of this review discusses current roadblocks of therapeutic cloning, both in science and biomedical ethics, as well as the main alternatives to therapeutic cloning.

Procedure for SCNT and characteristics of the ntESC

The procedure for SCNT does not differ from that of reproductive cloning (1). The host oocyte is arrested at metaphase II (2), and immobilized through light suction exerted by a pipette tip. A glass needle is used to remove a small piece of the zona pellucida and is reinserted through this puncture to extract the polar body and the oocyte nuclei. The incorporation of the somatic nuclei 
into the enucleated oocyte can be done through electrofusion, which is the application of an electric pulse to incorporate a mammalian cell into the oocyte (used to produce Dolly). Alternatively, a somatic nucleus can be injected in the perivitelline space, the fluid-filled region between the zona pellucida and the ooplasm, as was used for Cumulina, the first mouse cloned through SCNT. Mitosis occurs in vitro until the formation of the blastocyst, a fluid-filled hollow ball of cells (40-150 cells) to which is attached, from the inside, the embryoblast or inner cell mass from which ntESC are taken. Subsequent addition of cell-type specific markers and growth hormones promotes the differentiation of the ntESC into the desired cell-line to be implanted in vivo inside the nuclear donor for therapeutic purposes, in cell replacement therapy for instance. In vitro, the ESC can proliferate ad infinitum and are totipotent, capable of differentiating into any cell-type of the body, contrary to adult stem cells which are multipotent, namely committed to produce any type of cells pertaining to a particular lineage (3).

\section{Current legal status of therapeutic cloning in relation to reproductive cloning}

Laws regarding biomedicine are generally formulated in vague terms that do not distinguish reproductive from therapeutic cloning. The Convention on Human Rights and Biomedicine (Oviedo convention), formulated by the Council of Europe in 1997, is counterintuitive. Article 13 declares that "an intervention seeking to modify the human genome may be only undertaken for preventive, diagnostic or therapeutic purposes" and stipulates in Article 18 that "the creation of human embryos for research is prohibited (4)." The Protocol on Cloning, put forward in 1998 and signed by 19 European nations, bans reproductive cloning and was paradoxically signed by France and Germany, which both have permissive policies regarding the generation of human ntESC lines.

Committees are formed in different countries to debate and regulate cloning, such as the President's Council on Bioethics, created in the USA in 2002, which is a much less permissive group than the UK's Human Fertilization and Embryology Authority (HFEA). The legitimacy of the latter is being questioned by the Prolife movement under the pretext that they were not democratically elected (5). Canada's Assisted Human Reproduction Act, in vigor since 2004, allows stem cell research only on unimplanted embryos obtained from fertility clinics but forbids SCNT (6). Asia has the highest legal permissibility since the generation of human ntESC lines through SCNT is legal (25). Australia is currently reviewing its existing laws (7) to follow the Asian trend in Singapore, China and South Korea, and to legalize the generation of chimeras using human DNA.

Since both reproductive and therapeutic cloning require the in vitro generation of a human embryo, prohibiting reproductive cloning is likely to result in severely hindering medically important research based on therapeutic cloning. A worldwide ban on reproductive human cloning was proposed by France and Germany to the UN in 2001 and effective4 since September 2006 (4). A breakthrough in reproductive cloning was published a month earlier by Zavos and Illmensee, who injected a skin fibroblast nucleus from an infertile man into an oocyte provided by his wife. One out of three SCNT attempts was successful, and although the four-celled embryo failed to implant in utero, this is the "first evidence of the creation and transfer of a human cloned embryo for reproductive purposes (8)." One may infer, from the rigidity of the current legislature regarding therapeutic cloning and stem cell research, that legal constraints are motivated by the fear that scientific development will be faster than the legislative debate, which was almost the case with Zavros and Illmensee's breakthrough, and lead to the unregulated reproductive cloning of human beings.

\section{Promises of therapeutic cloning}

SCNT in the context of therapeutic cloning holds a huge potential for research and clinical applications including the use of SCNT product as a vector for gene delivery, the creation of animal models of human diseases, and cell replacement therapy in regenerative medicine. Furthermore, SCNT might, in the future, allow in vitro organogenesis and counteract senescence. The combination of therapeutic cloning and gene therapy offers a great potential for patient-specific rescue of a genetic mutation of the loss-of-function type, resulting in lowered or eliminated activity of a particular protein. Therapeutic cloning used in cell replacement therapy has the potential to create various types of tissues such as osteoblasts to counteract osteoporosis, and spinal cord regeneration following trauma, as shown by Deshpande et al, who transferred motor neurons derived from ESC to rats with a severed spinal cord (9). The resulting recovery of motility could lead to clinical applications for paralysis in humans through therapeutic cloning.

\section{Applications in regenerative medicine: recent breakthroughs for diabetes and neurodegenerative diseases}

Therapeutic cloning constitutes a promising tool in tissue engineering and might offer the possibility of synthesizing organs de novo, which would solve the problems of immune rejection and organ shortage for transplantation. The assembly of patient-specific cardiomyocytes, blood vessels and skin pieces fixed on 
a scaffold (39) holds great hope in the treatment of infarctus, atherosclerosis and severe burns, respectively. Consequently, the feasibility of de novo organogenesis based on SCNT depends on the elucidation of the tissue-specific molecular pathways mediating differentiation as well as the improvement of current SCNT and tissue engineering methods in order to recreate in vitro the complex three-dimensional organization and different intercellular interactions in organogenesis.

D'Amour et al designed in 2006 a five-step protocol enabling human embryonic stem cells to differentiate into endocrine cells producing most pancreatic hormones (10), including glucagon and insulin, with implications for use in cell replacement therapy for the treatment of diabetes mellitus. The combination of growth factors and differentiation markers added at each stage of the method were designed to duplicate pancreatic organogenesis in vivo, a breakthrough which could concretize the hope of generating organs using therapeutic cloning. According to this protocol, patientspecific ntESC lines would be differentiated into successive cell-type intermediates representative of pancreatic organogenesis, from endoderm to the terminally differentiated $\beta$-cell that would then be transplanted into the patient's pancreas to treat diabetesrelated hyperglycemia.

The recent success of therapeutic cloning in a mouse model of Parkinson's disease foreshadows clinical applicability in humans to treat neurodegenerative diseases and conditions involving demyelination. Parkinson's disease is characterized by the deterioration of dopaminergic neurons resulting in constant tremor and muscular stiffness impairing motility. Barberi et al derived, by SCNT with somatic nuclei from mouse cumulus and tail-tip cells, two ntESC lines which were induced to differentiate into motor, GABAminergic, serotonergic and dopaminergic neurons (11) forming synapses and displaying normal electrophysiological properties in vitro. The dopaminergic neurons were directly injected into the cortical striatum of mice with Parkinson-like lesions induced by 6-hydroxydopamine. Long-term behavioral rescue was observed, and $80 \%$ of the ntESC derived neurons were alive 8 week posttransplantation, contrary to only $40 \%$ for stem cellderived neurons. Hence, the therapeutic cloning approach was shown to be more permanent as a cell replacement therapy and could eventually be extended to the treatment of cortical atrophy resulting from stroke or Alzheimer's disease.

\section{REJUVENATING POTENTIAL}

It has been observed that the SCNT of the nucleus of a cell close to reaching senescence resets the lifespan of the cell, as seen by the ability of the resulting embryo to carry 31 rounds of division, compared to 33 for a wildtype embryo of the same developmental stage (39). The rejuvenating potential conferred by SCNT can be paradoxically thwarted by telomere shortening, which reflects both the biological age of the nuclear donor and the time during which the ntESC lines were grown (37), leading to premature aging also observed in cloned animals. However, the addition of a transgene containing the two coding regions needed for the production of telomerase could restore telomere lengths and thus increase the survival of the transplanted cells, which would increase the success rate of therapeutic cloning for regenerative medicine. This strategy needs more investigation to be feasible because, while telomere length would not trigger tumorigenesis (12), Stampfer et al showed that, knockout p16INK4a epithelial cells with no endogenous telomerase activity do not respond to the pro-apoptotic signals of the growth factor TGF- $\beta$ following the addition of high levels of hTERT, the telomerase catalytic subunit (13).

\section{GENERATING ANIMAL MODELS ANIMAL MODELS OF HUMAN DISEASE}

Animal models of human diseases can be designed through therapeutic cloning for research purposes. Although a viable nonhuman primate has not yet been produced by SCNT, the success of Mitalipov and Wolf in creating a monkey by embryonic cloning from the nucleus of an allogenic blastomere supported the possibility that, through gene targeting, genetic defects can be reproduced in a wild-type genome to express a loss of function (14). Hence, we are getting one step closer to patient-specific genetic engineering of animal models of human disease. With improved SCNT protocol, the nucleus of a patient's skin biopsy could be introduced into a primate or mouse enucleated oocyte so that the resulting clone expresses the condition in a patient-specific way. Hence, clinical testing would be done on the animal model to find an optimal treatment, such as the drug combination to treat epigeneticallytriggered cancer, highly variable among instances.

\section{CANCER DIAGNOSIS}

SCNT has applications in cancer research to identify whether a particular type of cancer arises from a genetic or an epigenetic defect (15), such as the demethylation of a tumor suppressor gene. The epigenetic modifications of chromatin structure in cancerous cells involve altered histone methylation, phosphorylation and deacetylation, as well as DNA methylation, which are reversible unlike genetic mutations. Supportive evidence for oncogenesis resulting from epigenetic features includes studies where normal mice blastula were obtained through SCNT from a skin malignancy (16) and a medullar 
tumor (17). These studies could lead to clinical applications for cancer diagnosis in humans since nuclear reprogramming signals from the host ooplasm variably reset the epigenetic profile of the nuclear donor DNA. The derivation through SCNT of a healthy patient-specific stem line would show that cancer onset was triggered by epigenetic alterations. Antimethylation drug, such as 5-aza-2'-deoxycytidine inhibiting DNA methyltransferases (18) that inactivate apoptotic genes in cancerous cells and histone deactylase inhibitors against oncogene overexpression are currently under clinical trial (15) as a potential anticancer therapy.

However, epigenetic resetting (15) following SCNT is likely to disrupt normal phenotype of the embryo-derived cell lines and the adult clone, the latter displaying an abnormally low body weight and expression level of MUP encoding genes (Major Urinary Proteins) as shown by Reik et al in the mouse. The epigenetic pattern of imprinted genes that was established during gametogenesis is lost through SCNT (20) and the inactivation of early genes directing embryogenesis can explain low embryo viability and poor efficiency in the derivation of autologous ntESC lines. Blelloch et al found out, from studies on neurons, that stem cells used as the nuclear donor have a higher success rate (21) than fully differentiated cells in the derivation of autologous embryonic cells. The introduction of a genetic mutation to reduce the function of DNA methyltransferase-1, as investigated by the same team, improved the production of ntESC due to resulting "global hypomethylation" (22) of genomic nuclear DNA.

\section{THERAPEUTIC CLONING IN THE CONTEXT OF GENE THERAPY: CURRENT HOPES AND DRAWBACKS}

SCNT from genetically modified nuclei obtained from a patient's skin biopsy, for example, is an efficient strategy to restore normal expression of a missing factor or to facilitate in vivo survival of the graft generated. For instance, patient-specific cardiomyocytes produced through SCNT will not integrate into the scarred heart tissue resulting from myocardial infarction. A proposed strategy (39) would be the genomic integration of an exogenous gene, prior to transplantation, encoding an anti-scarring factor (22) such as TGF-ß (transforming growth factor- $\beta$ ). In the case of haemophilia, characterized by a deficit in functional clotting factor IX and XIII (39), the addition of the genetically engineered missing DNA sequence, or the replacement of the dysfunctional gene through homologous recombination in a patient's biopsy prior to SCNT could produce patient-specific cell lines with a correction for the defect.
For instance, Duchenne Muscular Dystrophy (DMD) is an inheritable X-linked condition characterized by reduced intramuscular dystophin levels, causing cellular necrosis and weakening (23). Being a single-gene disorder, DMD can be treated by therapeutic cloning in combination with gene therapy to restore normal dystrophin production. In the case where ntESC are transplanted without prior differentiation in vitro, the insertion of a transgene encoding MyoD (35), a transcription factor responsible for commitment to the myogenic lineage, may promote muscle regeneration.

The combination of gene therapy and therapeutic cloning has exciting potential for the genetic rescue of missing alleles in heritable genetic disorders such as severe combined immunodeficiency (SCID), in which genetic mutations of specific genes such as RAG-1 and 2 , essential for the DNA recombination allowing immunoglobulin and lymphocyte polymorphism, render the immune system completely inefficient. Hochedlinger et al took a somatic nucleus from the tailtip of an SCID mouse-model, created through the double-knockout of the Rag-2 gene (recombinationactivating gene 2), and rescued the genetic defect through the insertion of two copies of the Rag- 2 gene by homologous recombination (24). SCNT was performed to clone viable Rag-2 (+/+) mice with a normal immune system, from which embryonic stem cells were differentiated in vitro into hematopoietic stem cells normally found in the bone marrow. Three weeks following transplantation into the Rag-2(-/-) knockout mouse model, partial rescue of immune function was observed, as well as the presence of lymphocyte precursors and functional antibodies. However, mature T lymphocytes were not observed, suspected to be due to selective differentiation of the transplanted stem cells into myeloid cells (bone marrow precursors) instead (25). Although more work needs to be done to elucidate the pathways leading to preferential differentiation in vivo, the combination of gene therapy for the rescue of a loss of function and therapeutic cloning to bypass graft rejection holds the potential to eventually cure other immune disorders. Oncogenic activation following transduction constitutes a major drawback to this approach. In 2002, the insertion of the transgene to treat X-linked SCID in the LMO2 oncogene caused the onset of leukemia in two out of seven patients recently treated (26). Repeated graft rejection, even when derived through SCNT, remains an unsolved problem in the case of autoimmune disorders such as pernicious anemia and multiple sclerosis.

\section{ROADBLOCKS OF THERAPEUTIC CLONING} Legal and funding issues

Legislative constraints and the subsequent lack of funding constitute a major impediment to the 
advancement of therapeutic cloning. For instance, although therapeutic cloning is not completely banned in the United States, federal funding is not permitted to be used in experiments involving the 20 cell lines in the NIH (National Institute of Health) registry (44) derived before August 9, 2001. Out of these cell lines approved by Bush, 12 died and the remaining is not useful for research purposes. Researchers have to therefore rely on the scarcity of private funding, although 4 American states, including California with a yearly investment of 295 millions, have a budget allowed specifically for stem cell research (44). Clinton expressed concern on chimera production through "experiments involving the mingling of human and non-human species" (58) but paradoxically all the cell lines in the NIH registry that got Bush's approval were grown on animal-feeder cell layers and therefore contain traces of animal contaminants.

Oocyte availability: regulations and ethical concerns

A major roadblock in the feasibility of human therapeutic cloning is the low availability of oocytes for research purposes. Currently, due to low SCNT efficiency, it is estimated that 280 human oocytes (35) would be needed in order to derive one observe patientspecific ntESC line. The Human Fertility and Embryo Authority, in England, allows women in fertility clinics to offer two oocytes for scientific research, provided that at least twelve oocytes are collected (25), although the extra oocytes taken are more likely to be donated for in vitro insemination. Oocyte donations are, by law, forbidden to be remunerated other than to reimburse the cost of the procedure (from 1000 to $2000 \$$ ) for ethical reasons. Substantial financial gain would incite poorer women to surrender of part of a finite supply of gametes, in addition to the risks incurred through surgerical removal of the oocytes and hormonal treatments. Ovarian hyperstimulation syndrome (OHSS) results, in most cases, from the administration of drugs such as gonadotropin-releasing hormone agonists (27), to induce the simultaneous maturation of multiple follicles into oocytes. OHSS can lead to cardio-respiratory difficulties, renal problems and internal hemorrhage, due to the accumulation of fluid in the abdominal cavity caused by abnormal vascular permeability in the vicinity of the ovaries (28), and occurs in 2 to $5 \%$ of the patients (29).

Fertility clinics are the major source of human oocytes for research. The aged oocytes that did not fertilize during in vitro trials are not optimal for SCNT, as investigated by Hall et al, who observed overexpression of genes encoding for meiotic spindles proteins and a lower cleavage efficiency (30) of aged oocytes versus fresh ones. After two years of debate, Harvard is the only group currently allowed to use oocytes collected for the sole purpose of research, with informed consent. Eggan and Melton intend to generate human ntESC lines from patients with diabetes, sickle cell anemia and amyotrophic lateral sclerosis (ALS), a progressive neurodegenerative condition targeting motor neurons (31).

\section{Possible solutions to the oocyte shortage for therapeutic cloning}

Interestingly, SCNT could provide a solution to low human oocyte availability and a promising therapeutic approach to circumvent infertility. As reported by Nagy and Chang, artificial gametes (32) can be created by haploidization, through SCNT into an enucleated oocyte ready to undergo meiosis upon induction. Tesarik et al incorporated the nucleus of a human cumulus cell into an enucleated allogenic oocyte. They got a $50 \%$ success rate in haploidization, and two out of the six artificial oocytes were successfully fertilized in vitro and thawed for possible implantation later on (33). However, abnormal chromosomal segregation and mitotic spindle assembly, as observed in mice, need to be resolved before haploidization through SCNT can be safely wide-spread in fertility clinics.

Once the molecular pathways of oocyte maturation are resolved, immature follicles could be collected postmortem (39) and induced to mature in vitro for research purpose. However, this option needs to be rigorously regulated, and is likely to stir an ethical controversy.

An alternative to low human oocyte availability would be to use an oocyte of a different species. Successful trials were done to generate blastocysts in vitro through the SCNT of skin fibroblast nucleus from different mammals (ungulates, rodents, pigs, monkey) (34) and human into an enucleated bovine oocyte. However, only $1 \%$ of the human-bovine hybrids developed beyond the 16-cell stage, allowing the derivation of a human ntESC line (39). The insertion of human nuclear genome into an animal oocyte, especially through electrofusion where both human and animal mitochondrial DNA coexist in the same ooplasm, raise objections among the detractors of therapeutic cloning, although the percentage of total residual animal DNA (nuclear and mitochondrial) is too low to consider the hybrid as a chimera.

\section{Mitochondrial heteroplasmy}

Immune rejection of the ntESC in cell replacement therapy is due to mitochondrial heteroplasmy as a consequence of SCNT since the nuclear donor and ooplasmic host cells are not autologous in most cases. Mitochondrial heteroplasmy is also a major cause of SCNT embryo inviability beyond the eight-cell stage because the mitochondrial-nucleus interactions necessary for the production of most mitochondrial 
proteins are disrupted due to inter-species incompatibility (35). Also, antigens such as Mta are encoded by the mitochondrial genome and trigger an auto-immune response targeting the hybrid (36) after transplantation. Cyclosporine A, an immunosupressor drug already used in organ transplantation (37), and the addition of either hemoglobin or B-mercaptoethanol might inhibit mitochondrial-induced apoptosis in the ntESC. Inter-species incompatibility can be circumvented to a certain degree if the donor and host species are closely related. For instance, embryonic cells derived from the injection of a human nucleus in a chimpanzee ooplasm were viable, contrarily to when SCNT was done with the ooplasm of a nonhuman primate such as the orang-utan (39).

The transfer of mitochondria isolated from patientspecific biopsies (39) might circumvent the immune rejection problem due to mitochondrial heteroplasmy, and a female patient could in theory donate both the somatic nucleus and oocyte necessary for cell replacement therapy in her own body. The latter option offers great promises since recent studies in bovine showed that autologous SCNT embryonic production was more efficient than when the nuclear donor and ooplasmic host are from allogenic origins, and epigenetic reprogramming occurs to a significantly less extend in autologous SCNT embryos (40).

\section{Transfer of animal contaminants}

The interspecies transmission of pathogens is a nonnegligible issue when injecting a human nucleus into the oocyte of another species, such as bovine or pig (41). For instance, the porcine endogenous retrovirus (PERV), although inoffensive in pigs, disrupts the transcription initiation of genes in humans, as demonstrated in vitro by Moalic et al, by integrating within the $\mathrm{CpG}$ islands of promoters (42). Gene therapy approaches are being designed to reduce the infectivity of PERV due to the mannose-rich N-glycan integrated in the viral capsule (43). Thus, through the insertion of genes such as ManIb and ManII, encoding mannosidases involved in N-glycan catabolism, the infectivity of PERV was significantly reduced but not annihilated in human cells.

Animal serum and non-proliferative mouse fibroblast used as feeder-cell layer to direct the development of the human ntESC (44) is problematic since animal contaminants can be transferred to the ntESC which in turn might trigger an immune response posttransplantation, thereby revoking the goal of therapeutic cloning.

$\mathrm{N}$-glycolylneuraminic acid (Neu5Gc) is a mammalian sialic acid (a sugar with acidic side-chains present in the membrane of all cells) not found in humans, although most of us have anti-Neu5Gc antibodies. When human
ntESC are grown on animal feeder cells or in contact with animal-derived serum, the stem cells incorporate enough Neu5Gc to potentially elicit an immune response (45) in vivo, hence killing the transplanted cells. Although the murine leukemia virus is not pathogenic (44) when transmitted from mouse feeder cells to human ntESC, non-cellular matrices are being designed to counteract the problem of animal contaminants. Ludwig et al developed a combination of human growth factors (TGFß, LiCl, bFGF, GABA, pipecolic acid which enhances receptor sensitivity to GABA) on a basal lamina reconstituted in vitro with human extracellular matrix components (collagen IV, laminin, vitronectin and fibronectin) (46) as a substitute for an animal feeder-cell layer. Neu5Gc was not reported in the cell lines cultured on this human matrix. In sum, the issue of pathogenic transmission is in the process of being solved, bringing one step further the potential for clinical application of therapeutic cloning in cell replacement therapy.

\section{Tumorgenesis and spontaneous differentiation}

NtESC are subjected to the same tumorigenicity potential as wild-type stem cells. The formation of teratomas, after in vivo transplantation, is due to copurification of pluripotent stem cells along with the wanted differentiated cells. Fujikawa et al noted tumor formation in the $\beta$-pancreatic cells transplanted in diabetic mice (47). The teratomas resulted from a low concentration of $0.2 \%$ Oct 4 and SSEA-1 positive cells, both markers of pluripotency (48) downregulated upon differentiation, indicating the presence of left-over undifferentiated stem cells. Although the hyperglycemia associated with type I diabetes was reversed, tumorgenesis occurred 20 days post-transplantation, rendering stem cells, whether wild-type or issued from therapeutic cloning, a non-viable option for clinical applications in this instance, unless better isolation methods for the exclusive purification of differentiated stem cells are designed.

\section{ETHICAL CONSIDERATIONS Destruction of IVF}

Therapeutic cloning and stem cell research stir an ethical controversy due to the source of embryonic stem cells, taken from aborted fetuses, unutilized zygotes (49) and embryos morphologically incapable of in utero implantation, the latter representing $60 \%$ of all embryos (50) created through IVF. Some consider the use of discarded embryos diminutive since they imply "recycling" life products, as implied by Bush's statement that "there is no spare embryo (29)."

The apparition of the primitive streak directing polarized development confers to the two-week embryo a higher moral status (51) as a potential human 
organism, compared to the earlier embryo at the stage of a randomly-organized group of cells. Consequently, laws prohibiting the culture of embryos for more than two-weeks, which marks the onset of gastrulation and the formation of the primitive streak, are in vigor in several countries such as the United States, based on a decision of the British Warnock Commission (29) in 1984.

The ethical debate on the moral impermissibility of deliberate destruction of an embryo can be circumvented by a new technique deviced by Chung et al. They successfully derived human ESC from a single cell without destroying the blastocyst in the process (52), using the same manipulations normally devoted to genetic screening in preimplantation embryos. This method seems to be promising for solving the ethical concern of killing a human embryo, rendering feasible the pre-natal generation of individual-specific cell lines for use in regenerative medicine later on in life. However, Chung's method does not modify the fate of the ex vivo embryo, since the latter has a slim chance of implantation.

\section{Moral status of the IVF embryo and the argument of potential}

The main ethical roadblock against therapeutic cloning is the destruction of the generated embryos in order to collect cells that would further be differentiated in vitro. Embryo destruction is viewed as morally objectionable by the Prolife partisans because they grant the early embryo potential for personhood following development to term. Knowing that only 1 to $2 \%$ of cloned mice produce viable organisms (53), the probability of producing a viable cloned human embryo is even slimmer. However, the detractors of research using embryos would argue that the potential for personhood ought not to be granted on the basis of probability because a minority - one out of three (54) of zygotes conceived by natural means might implant in utero and be carried to term. Hence, the argument from potential relies on possibility rather than probability and is based on the belief that morally significant human life beings at conception. According to Dawson and Singer, "since something is logically impossible only if its assertion involves a contradiction, it is not logically impossible for a human blastocyst in a laboratory to develop into a person (55)."

A counterargument put forth by the advocates of embryo research is that, left untouched, it is impossible that the in vitro embryo develops into the mature organism, and in utero implantation cannot occur if the transferred embryo reached the eight-celled stage and beyond (54). Nothing morally compelled one to generate a SCNT embryo that would have otherwise not existed, therefore we are not morally obligated to transfer the latter in utero. According to McMahan, "the idea that the potential to become a person confers a special moral status is plausible, if at all, only if the potential is identity-preserving (56). " He further argues that, contrary to the late-term embryo, the early embryo as an "insentient cluster of cells" has nonidentity potential since the latter is not identical in morphology to the mature organism, which possesses a neuronal network characteristic of higher mental life, is able to develop complex cognitive capacities including selfconsciousness and sentience, of which the early-term embryo is deprived. The destruction of an embryo of lower moral significance in the context of justified research to improve the quality of life of existing people of higher moral status ought to be viewed as morally permissible. Furthermore, under the philosophical point of view, "cell replacement therapy does not involve the destruction of an embryo but only its transformation into an embryonic cell line (57)."

The engineering of mouse blastocysts lacking the $\mathrm{Cdx} 2$ gene, otherwise needed for the generation of the midgut endoderm and trophoblast differenciation, results in non-viable embryos that spontaneously stop dividing, providing a criticized alternative to the destruction of embryos by deliberate human action.

\section{CONCLUSION}

Although several scientific roadblocks remain unsolved, the medical benefits that could be gained from treatments based on therapeutic cloning outweigh the ethical dilemma and calls for further improvements to be clinically applicable. In sum, therapeutic cloning features great potential as a histocompatible method for cell replacement therapy to restore motility following paralysis, counteract senescence, and repair damages done by stroke, myocardial infarction, liver cirrhosis, severe burns and osteoporosis to name a few. Used as an alternative to viral vectors, patient-specific cell lines derived through SCNT can be used in conjunction with gene therapy to treat conditions caused by genetic defects among which diabetes, hemophilia, sickle cell anemia, SCID, neurodegenerative disorders such as Parkinson, DMD and many more. Transgene insertion could be used before in vivo transplantation of the ntESC in order to enhance graft survival, differentiation and integration. Other applications of therapeutic cloning include the diagnosis of epigenetically triggered cancer and the tailoring of a treatment using SCNT, the creation of animal models of human diseases, and could eventually lead to tissue engineering of organs de novo. Main scientific difficulties include tumorigenicity, in vitro spontaneous differentiation, interspecies transfer of pathogens, low oocyte availability, epigenetic reprogramming of the genome, mitochondrial heteroplasmy and the possibility of graft rejection. 
Ethical controversy on the source and destruction of embryos as well as the contradictory legislations and scarcity of funding contribute to impede advancements in therapeutic cloning. Future considerations would be to unify federal and state laws, and establish a clear distinction between therapeutic and reproductive cloning in the redaction of laws pertaining to the SCNT generation of embryos. In this regard, a close understanding of the science and ethical issues pertaining to therapeutic cloning is necessary to ensure improvement in clinical applicability without falling into unregulated abuses.

\section{ACKNOWLEDGEMENTS}

I would like to thank Dr Philippe Gros, professor at the Department of Biochemistry of McGill, for his guidance and support.

\section{REFERENCES}

1. Snustad, Simmons. Principles of Genetics, 3rd Edition. John Wiley \& Sons Inc, 2003.

2. Illmensee K, Levanduski M, Zavos PM. Evaluation of the embryonic preimplantation potential of human adult somatic cells via an embryo interspecies bioassay using bovine oocytes. Fertil Steril. 2006 Apr;85 Suppl 1:1248-60.

3. Doss MX, Koehler CI, Gissel C, Hescheler J, Sachinidis A. Embryonic stem cells: a promising tool for cell replacement therapy. J Cell Mol Med. 2004 Oct-Dec;8(4):465-73. Review.

4.. Mahnoush H. Arsanjani. Negociating the UN Declaration on Human Cloning. The American Journal of International Law, Vol.100, No.1. (Jan 2006), pp.164-179, accessed online from JSTOR archives.

5. Pattinson SD. University of Sheffield, Sheffield Institute of Biotechnological Law and Ethics (SIBLE). Some problems challenging the UK's Human Fertilisation and Embryology Authority, Med Law. 2005 Jun;24(2):391-401.

6. Center for Genetics and Society. Canadian Parliament Approves the "Assisted Human Reproduction Act, "A Model of Responsible Policy. http://www.genetics-andsociety.org/policies/other/canada.html.

7. Dennis C. Australia considers changing laws to allow therapeutic cloning. Nat Med. 2006 Feb;12(2):156.

8. Zavos PM, Illmensee K. Possible therapy of male infertility by reproductive cloning: one cloned human 4-cell embryo. Arch Androl. 2006 Jul-Aug;52(4):243-54.

9. Liang P, Jin LH, Liang T, Liu EZ, Zhao SG. Human neural stem cells promote corticospinal axons regeneration and synapse reformation in injured spinal cord of rats. Chin Med J (Engl). 2006 Aug 20;119(16):1331-8.

10. D'Amour KA, Bang AG, Eliazer S, Kelly OG, Agulnick AD, Smart NG, Moorman MA, Kroon E, Carpenter MK, Baetge EE. Production of pancreatic hormone-expressing endocrine cells from human embryonic stem cells. Nat Biotechnol. 2006 Oct;

11. Barberi T, Klivenyi P, Calingasan NY, Lee H, Kawamata H, Loonam K, Perrier AL, Bruses J, Rubio ME, Topf N, Tabar V, Harrison NL, Beal MF, Moore MA, Studer L. Neural subtype specification of fertilization and nuclear transfer embryonic stem cells and application in parkinsonian mice. Nat Biotechnol. 2003 Oct;21(10):1200-7.

12. Sharpless NE and DePinho RA, Telomeres, stem cells, senescence, and cancer, J. Clin. Invest 2004; 113:160-168.

13. Stampfer M, Garbe J, Levine G, Lichtsteiner S, Vasserot A,
Yaswen P. Expression of the telomerase catalytic subunit, hTERT, induces resistance to transforming growth factor $B$ growth inhibition in p16INK4A(-) human mammary epithelial cells. PNAS 2001 Apr 10;98(8):4498-503.

14. Mitalipov SM, Wolf DP. Nuclear transfer in nonhuman primates, Methods Mol Biol. 2006;348:151-68.

15. Novak K. Therapeutic cloning gives silenced genes a second voice. Nat Med. 2004 Oct;10(10):100.

16. Hochedlinger K, Blelloch R, Brennan C, Yamada Y, Kim M, Chin L, Jaenisch R. Reprogramming of a melanoma genome by nuclear transplantation. Genes Dev. 2004 Aug 1;18(15):1875-85

17. Li L, Connelly MC, Wetmore C, Curran T, Morgan JI. Mouse embryos cloned from brain tumors. Cancer Res. 2003 Jun 1;63(11):2733-6.

18. Fan J, Kodama E, Koh Y, Nakao M, Matsuoka M. Halogenated thymidine analogues restore the expression of silenced genes without demethylation. Cancer Research 2005; 65 (15): $6927-$ 6933.

19. Reik W, Romer I, Barton SC, Surani MA, Howlett SK, Klose J. Adult phenotype in the mouse can be affected by epigenetic events in the early embryo. Development. 1993 Nov;119(3):933-42.

20. Jaenisch R. Human cloning - the science and ethics of nuclear transplantation, Whitehead Institute for Biomedical Research. N Engl J Med 2004 Dec 30;351(27):2787-91.

21. Blelloch R, Wang Z, Meissner A, Pollard S, Smith A, Jaenisch R. Reprogramming efficiency following somatic cell nuclear transfer is influenced by the differentiation and methylation state of the donor nucleus.1: Stem Cells. 2006 Sep;24(9):2007-13.

22. Liu W, Wang DR, Cao YL. TGF-beta: a fibrotic factor in wound scarring and a potential target for anti-scarring gene therapy. Curr Gene Ther 2004 Mar;4(1):123-36. Review.

23. Huard J, Cao B, Qu-Petersen Z. Muscle-derived stem cells: potential for muscle regeneration. Birth Defects Res C Embryo Today 2003 Aug; 69 (3):230-7. Review.

24. Rideout WM 3rd, Hochedlinger K, Kyba M, Daley GQ, Jaenisch R. Correction of a genetic defect by nuclear transplantation and combined cell and gene therapy. Cell. 2002 Apr 5;109(1):17-27.

25. Hall VJ, Stojkovic P, Stojkovic M. Using therapeutic cloning to fight human disease: a conundrum or reality? Stem Cells. 2006 Jul; 24(7):1628-37. Review.

26. Chinen J, Puck JM. Successes and risks of gene therapy in primary immunodeficiencies. J Allergy Clin Immunol. 2004 Apr;113(4):595-603. Review.

27. Acevedo B, Gomez-Palomares JL, Ricciarelli E, Hernández ER. Triggering ovulation with gonadotropin-releasing hormone agonists does not compromise embryo implantation rates. Fertility and Sterility 2006 Dec; 86(6):1682-7.

28. Mathur R, Kailasam C, Jenkins J. Review of the evidence base of strategies to prevent ovarian hyperstimulation syndrome. Human Fertility 2007; 10(2):75 - 85.

29. Okie S. Stem-cell research--signposts and roadblocks. N Engl J Med. 2005 Jul 7;353(1):1-5.

30. Hall VJ, Compton D, Stojkovic P, Nesbitt M, Herbert M, Murdoch A, Stojkovic M. Developmental competence of human in vitro aged oocytes as host cells for nuclear transfer. Human Reproduction 2006 Sept 6.

31. Holden C. Stem cell research. Harvard cloners Get OK to proceed with caution. Sc ience 2006 Jun 16;312(5780):1584.

32. Nagy ZP, Chang CC. Artificial Gametes,.Theriogenology 2006 Oct 19.

33. Tesarik J, Nagy ZP, Sousa M, Mendoza C, Abdelmassih R. Fertilizable oocytes reconstructed from patient's somatic cell nuclei and donor ooplasts. Reprod Biomed Online. 2001;2(3):160-164. 
34. Dominko T, Mitalipova M, Haley B, Beyhan Z, Memili E, McKusick B. First NL.Bovine oocyte cytoplasm supports development of embryos produced by nuclear transfer of somatic cell nuclei from various mammalian species. Biol Reprod. 1999 Jun;60(6):1496-502.

35. Colman A, Kind A. Therapeutic cloning: concepts and practicalities. PPL Therapeutics, Trends Biotechnol. 2000 May;18(5):192-6.

36. Hall VJ, Stojkovic P, Stojkovic M. Using therapeutic cloning to fight human disease: a conundrum or reality? Stem Cells. 2006 Jul;24(7):1628-37. Review.

37. Sharov VG, Todor A, Khanal S, Imai M, Sabbah HN, Cyclosporine A attenuates mitochondrial permeability transition and improves mitochondrial respiratory function in cardiomyocytes isolated from dogs with heart failure. J Mol Cell Cardiol. 2006 Oct 26;

38. Park ES, Hwang WS, Jang G, Cho JK, Kang SK, Lee BC, Han JY, Lim JM. Incidence of apoptosis in clone embryos and improved development by the treatment of donor somatic cells with putative apoptosis inhibitors. Mol Reprod Dev. 2004 May;68(1):65-71

39. Lanza RP, Cibelli JB, West MD. West Prospects for the use of nuclear transfer in human transplantation. Nature Biotechnology 1999; 17:1171 - 1174

40. Yang XY, Li H, Ma QW, Yan JB, Zhao JG, Li HW, Shen HQ, Liu HF, Huang Y, Huang SZ, Zeng YT, Zeng F. Shanghai Institute of Medical Genetics. Improved efficiency of bovine cloning by autologous somatic cell nuclear transfer. Reproduction. 2006 Nov;132(5):733-739.

41. Lanza RP, Cibelli JB, West MD. Human therapeutic cloning. Nat Med. 1999 Sep;5(9):975-7.

42. Miyagawa S, Nakatsu S, Hazama K, Nakagawa T, Kondo A, Matsunami K, Yamamoto A, Yamada J, Miyazawa T, Shirakura R. A novel strategy for preventing PERV transmission to human cells by remodeling the viral envelope glycoprotein. Xenotransplantation. 2006 May;13(3):258-63.

43. Moalic Y, Blanchard Y, Felix H, Jestin A. Porcine endogenous retrovirus integration sites in the human genome: features in common with those of murine leukemia virus. Journal of Virology, 2006 Nov;80(22):10980-8.

44. Gruen L, Grabel L. Concise review: scientific and ethical roadblocks to human embryonic stem cell therapy. Stem Cells. 2006 Oct; 24(10):2162-9.

45. Martin MJ, Muotri A, Gage F, Varki A. Glycobiology Research and Training Center and Department of Medicine. University of California. Human embryonic stem cells express an immunogenic nonhuman sialic acid. Nat Med. 2005 Feb;11(2):228-32.

46. Ludwig TE, Levenstein ME, Jones JM, Berggren WT, Mitchen ER, Frane JL, Crandall LJ, Daigh CA, Conard KR, Piekarczyk MS, Llanas RA, Thomson JA. WiCell Research Institute. Derivation of human embryonic stem cells in defined conditions. Nat Biotechnol. 2006 Feb;24(2):185-7.

47. Fujikawa T, Oh SH, Pi L, Hatch HM, Shupe T, Petersen BE. Teratoma formation leads to failure of treatment for type I diabetes using embryonic stem cell-derived insulin -producing cells. American Journal of Pathology 2005 Jun;166(6):1781-91.

48. Mimeault M, Batra SK. Recent Advances on the Significance of Stem Cells in Tissue Regeneration and Cancer Therapies. Stem Cells. 2006;24(11):2319-2345.

49. Ostrer H, Wilson DI, Hanley NA. Human embryo and early fetus research, Clin Genet. 2006 Aug; 70(2):98-107.

50. Landry DW, Zucker HA. Embryonic death and the creation of human embryonic stem cells, J Clin Invest. 2004 Nov; 114(9):1184-6. Review.

51. Human Cloning and Human Dignity: An Ethical Inquiry. The President's Council on Bioethics. Washington, D.C., July 2002, position number one of the section entitled "the Moral Case for Cloning-for-Biomedical-Research."

http://www.bioethics.gov/reports/cloningreport/fullreport.html.

52. Alberio R, Campbell KH, Johnson AD. Reprogramming somatic cells into stem cells. Reproduction 2006 Nov;132(5):709-20.

53. Wakayama T. On the road to therapeutic cloning. Nat Biotechnol. 2004 Apr; 22(4):399-400.

54. Roberts PC, Lowe C. Where have all the conceptions gone? Lancet 1975; 498-499.

55. Singer P, Karen Dawson. IVF Technology and the Argument from Potential, Philosophy and Public Affairs. 1988; 17(2):8990.

56. McMahan J. The Ethics of Killing - Problems at the Margins of Life, Oxford University Press, 2002, p.308

57. Lanza RP, Caplan AL, Silver LM, Cibelli JB, West MD, Green RM. The ethical validity of using nuclear transfer in human transplantation. JAMA. 2000 Dec 27;284(24):3175-9, Ethics Institute, Dartmouth College, Hanover.

58. Meissner A, Jaenisch R. Generation of nuclear transfer-derived pluripotent ES cells from cloned Cdx2-deficient blastocysts. Nature 2006 Jan 12; 439(7073):212-5.

Charlotte Kfoury (B. Sc 2007) is graduating this year with an Honours degree in Biochemistry. She is looking forward to studying medicine at McGill this year, and hopes to do more research in the future. 